\title{
An Ergonomic Approach for Designing of an Industrial Trolley with Workers Anthropometry
}

\author{
Subrata Talapatra, Nourin Mohsin, Mehrab Murshed \\ Department of Industrial Engineering and Management (IEM), Khulna University of Engineering \& Technology (KUET), \\ Khulna, Bangladesh \\ Email: subrata@iem.kuet.ac.bd
}

How to cite this paper: Talapatra, S., Mohsin, N. and Murshed, M. (2019) An Ergonomic Approach for Designing of an Industrial Trolley with Workers Anthropometry. American Journal of Industrial and Business Management, 9, 2156-2157. https://doi.org/10.4236/ajibm.2019.912143

Received: September 11, 2019

Accepted: December 14, 2019

Published: December 17, 2019

Copyright $\odot 2019$ by author(s) and Scientific Research Publishing Inc. This work is licensed under the Creative Commons Attribution International License (CC BY 4.0).

http://creativecommons.org/licenses/by/4.0/

\begin{abstract}
Industrial trolley is an essential material handling equipment which is available in many industries and carries up to 1 ton weight. But in some cases, these trolleys are not ergonomically designed and so many workers suffer from various musculoskeletal disorders (MSDs). The purpose of this study is to find the mismatch between trolley dimension and anthropometric data. Anthropometric measurements (2) of 50 workers and dimensions (2) of industrial trolley were taken and so these were differentiated. Mismatches were found out by doing chi-square test. According to a survey, workers' experiencing pain was found out in their various body parts. It was found that wheel radius and handle height were too short which cause discomfort to the workers. These inspections suggest dimensions for the design of an industrial trolley so that comfort and efficiency of the workers can be ensured.
\end{abstract}

\section{Keywords}

Measurement of Anthropometry, Industrial Trolley, Trolley Design, Mismatch, Musculoskeletal Disorders, Dimensions of Trolley

\section{Introduction}

This research studies about designing of an industrial trolley. Industrial trolleys are essential parts of material handling that are found in various industries. They have an important role in various kinds of industrial purposes. Industrial trolleys should be made according to the anthropometric measurements of the workers. Various kinds of musculoskeletal disorders, posture defect and other causes are the reasons for the discomfort of the workers. These MSDs occur because of the mismatches between trolley dimensions and workers' anthropometry. To reduce 
the MSDs, there must be higher percentage of matches between anthropometric data and trolley dimension. For this purpose, anthropometric measurement is very much essential. As workers spend most of the time on working in an industry, this research is very much essential not only for physical health of workers but also to enhance their efficiency.

In this research, a trolley design is proposed that will decrease the MSD's. For this purpose, first, the anthropometric measurements of the workers were collected and then two parameters of the existing trolley were identified on which this research focuses on. According to the anthropometric dimensions, these two parameters were evaluated and the proper ergonomic dimension was proposed.

\section{Literature Review}

Study found that an intelligent platform trolley can be made to research things and analyze various loads by concentrating stress (static) at right panel, connectors, front and back ends of trolley [1]. Communication interaction and also obstacles can be avoided by using raspberry pi and also a robot for making a trolley. This is made to track target [2]. Research found that an ergonomic chair can improve efficiency, reduce disease caused by infection and other MSDs problems. It can also improve nutrition level of elderly persons [3]. A single and double wheel trolley can be used to reduce lifting stress that is only on flat ground and also a mechanism for transporting over stairs of masses may be done by it [4]. In garments industries management of total quality is a prerequisite for the safety of the workers also for management system implementation which is normally integrated [5] [6].

Some analyses pointed out that mismatches can be found between anthropometric measurements of school furniture and anthropometric measurements of primary school students, university furniture and anthropometric measurements of students of many universities and these mismatches can be reduced by using t-test analysis, mismatch equation and also using chi-square distribution [7] [8] [9] [10].

Again some studies found out that in a manufacturing system initial force and height range of handle is calculated while pushing a trolley [11]. Another research recognized that workers may suffer from MSDs for wrong design of trolleys and hence handle height is calculated to reduce back pain and other MSDs of workers [12]. Work efficiency is increased by using a tool called pig in a pigging operation while handling a trolley [13]. According to another research in a material handling operation a trolley is used to lift a self-weight job keeping in the shortest distance [14]. Also quality management is important for increasing workers' efficiency. But there are some obstacles behind it [15]. These problems have to be understood properly for ensuring workers' safety [16].

Pulling and pushing are one of the most essential parts in an industrial world because of variety of material handling equipments that are being largely used [17]. Again some studies found that in agricultural works ergonomic hand tools 
are used to reduce the MSDs and other injuries of the workers [18]. Again another research found out that different types of injuries like elbow and shoulder injuries are related to each other [19]. Some analysis found out the external force on wheel chair loading system [20]. An ergonomically designed trolley eliminates MSDs and improves efficiency [21]. Another study suggested that in cylindrical trolleys various things affect handle design but best configuration can not be found by this [22]. In marble cutting process, a transfer trolley can be designed and manufactured in marble industry that can reduce pain of workers [23]. A well developed and creative trolley can perform as both the airport trolley and shopping mall trolley [24] [25].

In short distance movement, various types of office trolleys can be used [26]. In horizontal pulling action handle design has great influence [27]. To push a cart 3D hand forces are calculated [28].

According to ergonomic study, in dryland weeder (push pull system) that is manually operated, optimum handle height is determined [29]. Other researches considered that various industrial transport carts are ergonomically made by proper handle and wheel design and to find out optimum force application, new design is being used [30]. In pushing and pulling system, handle interface for biochemical analysis is being used [31]. Study pointed out wheel design, handle height design, weight of load, direction of movement, move phase, type of floor in accordance with ergonomic rule and also their effect [32]. However, a meal mart in hospital is made by following ergonomic rules that reduce problems of previously made mart [33]. Ergonomic Compatibility also can be determined in mini-buses [34]. Some analyses found that safety awareness has a great importance for reducing health hazard of workers [35]. In garments industry various critical factors are included for TQM implementation that is important for ensuring quality of work to be done [36].

Shoulder motion range can be realized by reliability test [37]. Hand tool is designed by considering grip diameter [38] and in horizontal pulling action handle design has great influence [39]. According to ergonomic consideration wheelbarrows, wheel, truck are designed and various types of mobile trolleys are also designed for material handling system [40].

\section{Methods}

\subsection{Sample Population}

From machine shop of an industry in Khulna, Bangladesh, sample population was taken as in the whole machine shop uses industrial trolley. The anthropometric measurements were taken from 50 workers (male). Only male workers were taken as the sample population because there were no female workers found in the machine shop. Permission was granted for the workers to take participation in this research by the managing director of the industry.

The age of the workers was between 25 years and 42 years, the mean of their age being 34 years. Population distribution of study in accordance with age and designation is explained in Table 1. Using Equation (1), the sample size was 
calculated (Odunaiya, Owonuwa and Oguntibeju 2014). Here, it can be seen that $n=$ anticipated sample size, $N=$ population size, and $e=$ level of accuracy. In this study, $N=50, e=5 \%$ at $95 \%$ confidence level.

$$
n=N /\left(1+N e^{2}\right) \text {. }
$$

From the equation, the minimum acceptable sample size was calculated to be 44 or more. The available workers number is 50 having no physical issues and the probability of unsuitable measurements of data or inappropriate deviation in the data was reduced. The workers were given assurance of their safety before the measurements were taken.

\subsection{Survey Performed}

A survey was performed where questions were in a yes/no format. Pain experienced by workers was found out by this survey which helped to find out the dimensional problem of the industrial trolleys. It was found that because of handle height lower back pain occurred and for wheel MSDs occurred among the workers.

It was also found from the survey that most of the workers who were suffering from back pain, used the trolley. But while using the trolley, they had to bend unexpectedly to drive the trolley, and so consistent use of the trolley aided in the development of back pain among its users. Also, because of the improper wheel radius, the workers had to push the trolley with excessive force which leads to MSDs among the workers. Figure 1 demonstrates the percentage of pain experienced by the workers.

Table 1. Distribution population according to age and designation.

\begin{tabular}{ccc}
\hline Age range & Designation & No. of workers \\
\hline $25-29$ & Technician & 24 \\
$30-34$ & Foreman & 16 \\
$35-39$ & Supervisor & 8 \\
$40-42$ & Assistant manager & 2 \\
\hline
\end{tabular}

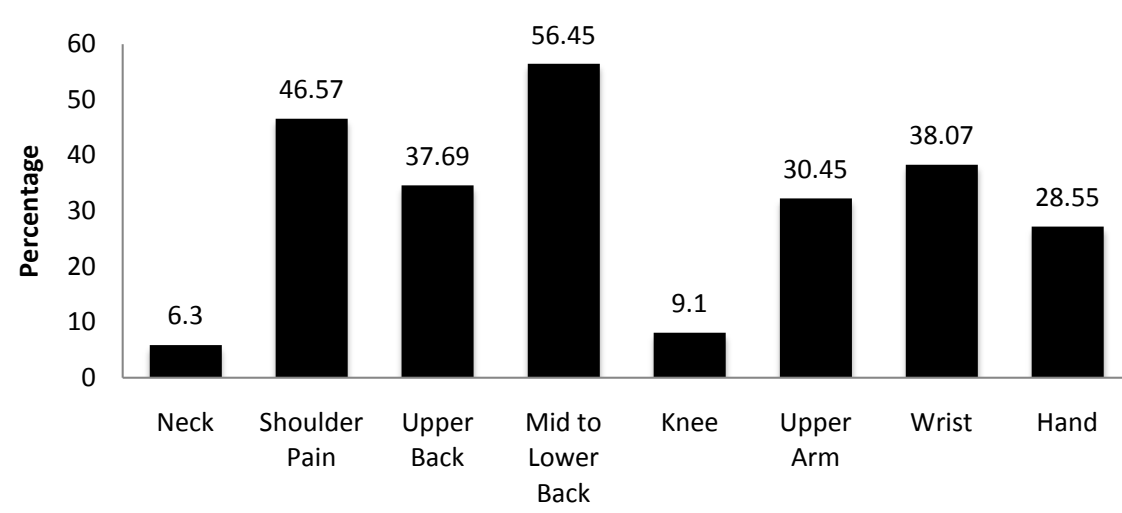

Experiencing Pain

- Percentage

Figure 1. Percentage of pain experienced by the workers. 


\subsection{Anthropometric Procedures, Dimensions and Equipments}

According to studies (S. Pheasant, 2003; Kroemer and Kroemer, 1997; Weiner and Lourie, 1969), 2 anthropometric measurements of the workers in the industry in standing in a straight posture were taken by the researchers along with assistant. The measurements were taken at barefoot. The assistant reduced intra and inter observer error. Dimensions were taken in centimeter $(\mathrm{cm})$. Figure 2 shows the anthropometry of workers.

An anthropometric tool available in the ergonomics laboratory of Khulna University of Engineering \& Technology's Department of Industrial Engineering and Management was used. Also, slide calipers and tape were taken for taking anthropometric dimensions. These measurements were taken precisely and accurately.

The measurements were taken in 2 weeks and these were taken twice to ensure that there is no error.

Following anthropometric measurements were taken for the purpose of the study from source (Standard 2003):

Stature (S) Natural height of a person

Elbow Height $(\mathrm{EH}) \quad$ Distance from the floor surface to underside of elbow taken vertically

\subsection{Measurement of Trolley}

As local workshops manufactured or produced most of the trolleys, they are not ergonomically designed because manufacturers have lack of experience and knowledge about ergonomic facts and designs. Following parameters of an industrial trolley were considered.

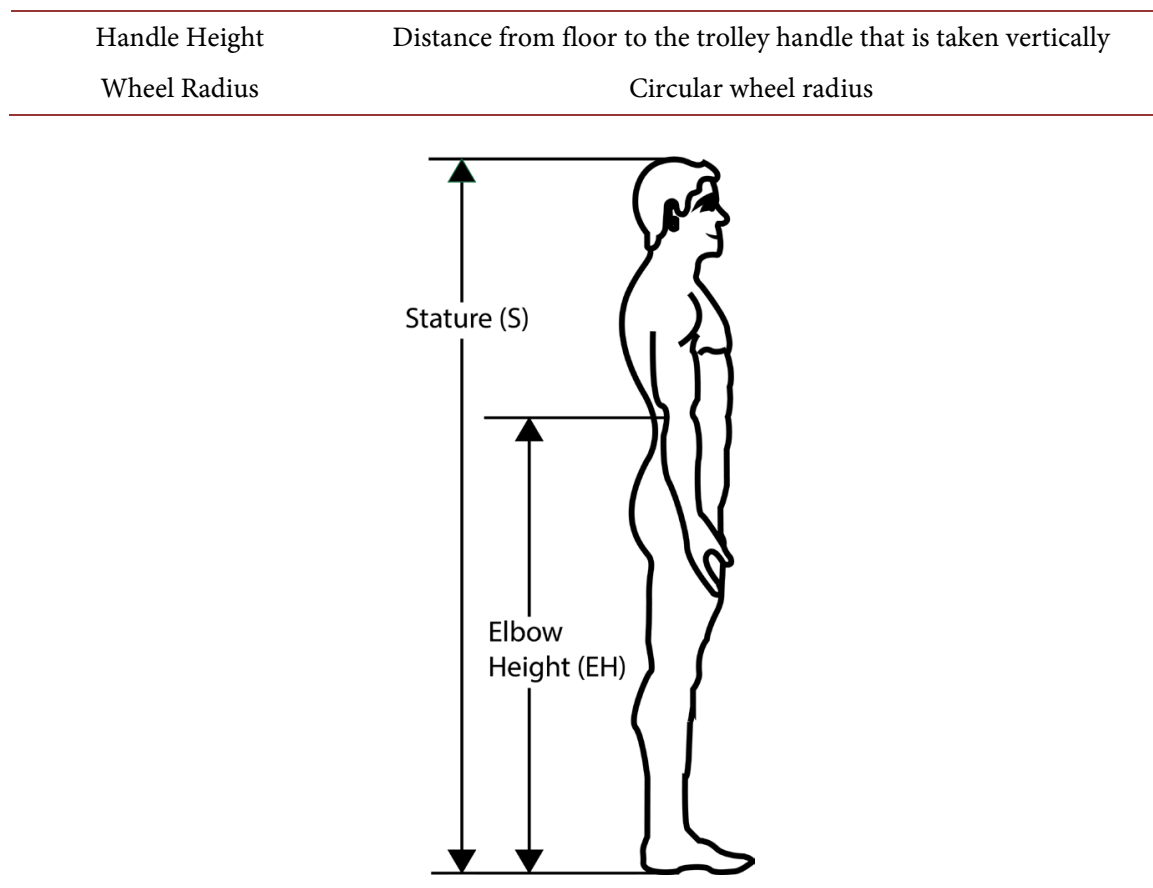

Figure 2. Anthropometry of workers. 


\subsection{Mismatch Equations between Dimensions of Industrial Trolley and Workers' Anthropometry}

Following ergonomic rule was evaluated to perform the mismatch equation.

\section{Stature (S) against Handle Height ( $\mathrm{HH})$}

Handle height is corelated to Stature. Elbow height can be used as a proportion of overall human height or stature (S) that ranges between $66 \%$ and $77 \% .3 \mathrm{~cm}$ allowance was added for shoe to the condition as workers wore shoes while taking measurements [9]. So the following relationship between $\mathrm{S}$ (Stature) and $\mathrm{HH}$ (Human Height) is expressed in Equation (2),

$$
(0.66 \mathrm{~S}+3)<\mathrm{HH}<(0.77 \mathrm{~S}+3) .
$$

\subsection{Levels of Compatibility}

There are three kinds of conditions that were considered: 1) High mismatch which means anthropometric measurements are found to be lower than the evaluated lowest limit; 2) Low mismatch which means anthropometric measurements are found to be higher than the evaluated highest limit; and 3) Match which means anthropometric measurements remain within the evaluated limits.

\section{Data Analysis}

\subsection{Measurement of Anthropometry of Workers}

The calculation of 2 anthropometric measurements of industry workers such as minimum (minm), maximum (maxm), standard deviation (SD) and percentile values (5th, 50th and 95th) were performed by SPSS v25. Table 2 shows the measurements of anthropometry of workers in $\mathrm{cm}$.

\subsection{Existing Trolley Dimension}

To calculate potential mismatch between workers' anthropometric data and existing industrial trolley dimensions, it is important to learn about the existing dimensions. Table 3 shows existing trolley dimensions in $\mathrm{cm}$ following standard procedure.

Table 2. Anthropometric dimensions of workers.

\begin{tabular}{|c|c|c|c|c|c|c|c|}
\hline \multirow{2}{*}{ Dimension } & \multirow{2}{*}{ Minimum } & \multirow{2}{*}{ Maximum } & \multirow{2}{*}{$\mathrm{SD}$} & \multirow{2}{*}{ Mean } & \multicolumn{3}{|c|}{ Percentile Values } \\
\hline & & & & & 5 th & 50 th & 95th \\
\hline Stature & 154.34 & 172.72 & 4.23 & 166.61 & 158.65 & 167.16 & 172.13 \\
\hline Elbow Height & 121.84 & 135.99 & 3.25 & 131.28 & 125.16 & 131.71 & 135.53 \\
\hline
\end{tabular}

Table 3. Existing trolley dimension.

\begin{tabular}{cc}
\hline Trolley Parameters & Dimensions $(\mathrm{cm})$ \\
\hline Handle Height (HH) & 113.2 \\
Wheel Radius (WR) & 2.8 \\
\hline
\end{tabular}




\subsection{Calculation of Mismatch Equations of Existing Trolley}

Dimension of trolley handle height was evaluated and match and mismatch percentage values were listed. Table 4 shows the potential mismatch and match percentage of the existing industrial trolley.

\subsection{Chi-Square Test between Anthropometric Data and Trolley Dimensions}

Chi-square test was performed and calculated statistically (Spiegel, Stephens, 2003) to find out the relationship between trolley dimensions and anthropometric dimensions of the workers. Table 5 shows chi-square test having 2 dimensions of human body with percentile values and also observed and expected values.

\section{Results and Discussion}

\subsection{Anthropometric Measurements Analysis of Workers}

Table 2 shows anthropometric dimensions of workers. Mean stature, mean elbow height, mean shoulder height, mean grip strength were the following 166.61 $\pm 4.23,131.28 \pm 3.25,39.56 \pm 1.39,4.07 \pm 0.276$. The percentile values for Stature were 158.65, 167.16, 172.13; the percentile values for elbow height were 125.16, $131.71,135.53$; the percentile values for shoulder breadth were $37.38,39.69$, 41.72; the percentile values for grip breadth were $3.63,4.12$, and 4.49 .

\subsection{Analysis of Mismatch Equations}

Table 4 shows that there is $52 \%$ mismatch for handle height.

From Figure 3, it was found that the existing handle height was not compatible with the anthropometric measurements of the workers as the mismatch percentage was $52 \%$ which was not acceptable, as our target was to minimize the mismatch as far as possible.

\subsection{Chi-Square Test Analysis}

Existing trolley dimension was compared with anthropometric data by chi-square test where the calculated values were weighed against critical values of chi-square

Table 4. Match and mismatch percentage of trolley dimensions.

\begin{tabular}{ccccc}
\hline Trolley Dimensions & Low Mismatch & High Mismatch & Total Mismatch & Total Match \\
\hline Handle Height $(\mathrm{HH})$ & 52 & 0 & 52 & 48 \\
\hline
\end{tabular}

Table 5. Chi-square values for trolley dimension.

\begin{tabular}{|c|c|c|c|c|c|c|c|}
\hline \multirow{2}{*}{ Association } & \multirow{2}{*}{ Value } & \multicolumn{3}{|c|}{ Percentile Value } & \multirow{2}{*}{$\begin{array}{c}\text { Chi-square } \\
\text { Values }\end{array}$} & \multirow{2}{*}{$\begin{array}{l}\text { Chi-square } \\
(\mathrm{DF}=2)\end{array}$} & \multirow{2}{*}{ Decision } \\
\hline & & 5 th & 50th & 95th & & & \\
\hline Elbow Height (EH) and & Observed & 125.16 & 131.71 & 135.53 & \multirow{2}{*}{7.14} & \multirow{2}{*}{5.99} & \multirow{2}{*}{ Reject } \\
\hline Handle Height $(\mathrm{HH})$ & Expected & 117.47 & 113.20 & 114.55 & & & \\
\hline
\end{tabular}




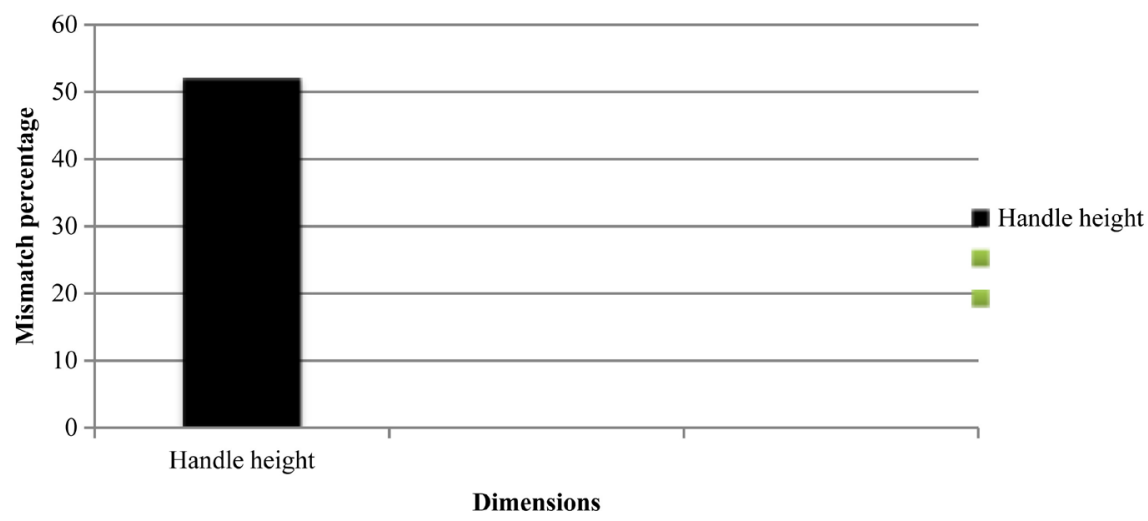

Figure 3. Mismatch percentage of dimensions of industrial trolley.

(0.103), degree of freedom (2) and 95 percent confidence level (5.33). For handle height, calculated value is larger than 0.103 (critical value). So the result was "Reject".

\subsection{Proposed Furniture Dimensions}

As there were mismatches between trolley dimension and anthropometric measurements it was necessary to redesign of the existing trolley with proper anthropometric measurement to reduce the pain experienced by the workers.

Table 6 shows the mismatch percentage of proposed dimension. For handle height mismatch percentage is $2 \%$ and so there is $98 \%$ match where existing wheel radius was found to be $2.82 \mathrm{~cm}$.

From Figure 4, it is found that the minimum wheel radius for a load of 1 ton should have been $4 \mathrm{~cm}$. But the existing radius is $2.82 \mathrm{~cm}$. As minimum requirement for wheel radius for 1 ton load is not satisfied, the wheel radius is considered as $4 \mathrm{~cm}$ in the proposed trolley dimension (Butin, Vasiliev, Tumasov, \& Bagichev, 2018). Now the author recommends cast iron as a trolley material considering cost and other aspects. $2 \mathrm{D}$ view of an industrial trolley is shown in Figure 5. However, a comparison of existing and proposed dimension of an industrial trolley is shown in Figure 6.

\section{Conclusions}

Workers' efficiency and comfort at work place largely depend upon MSDs risk factors, anthropometric measurements and trolley dimension. Existing trolley dimensions had mismatch with the anthropometric measurements of the workers and so the trolley was designed again to reduce the MSDs of the workers.

2 anthropometric measurements of 50 workers were taken. Survey showed that MSDs occurred among the workers for 2 parameters (Handle height, wheel radius). Stature and elbow height were evaluated to point out the mismatch between trolley and anthropometric measurement of workers. Chi-square test was performed to find out the connection between the anthropometric dimension and trolley dimensions. Handle height was not accepted because of the higher percentage value. Also, wheel radius was found to be too small. 
Table 6. Proposed measurements of trolley dimensions.

\begin{tabular}{cccccc}
\hline \multirow{2}{*}{$\begin{array}{c}\text { Trolley } \\
\text { Dimension }\end{array}$} & Proposed & Criteria & \multicolumn{3}{c}{ Mismatch Percentage } \\
\cline { 3 - 5 } Handle Height & 122.5 & $\begin{array}{c}\text { Average of 50th percentiles of } \\
\text { higher and lower elbow heights }\end{array}$ & 0 & High & Total \\
\hline
\end{tabular}

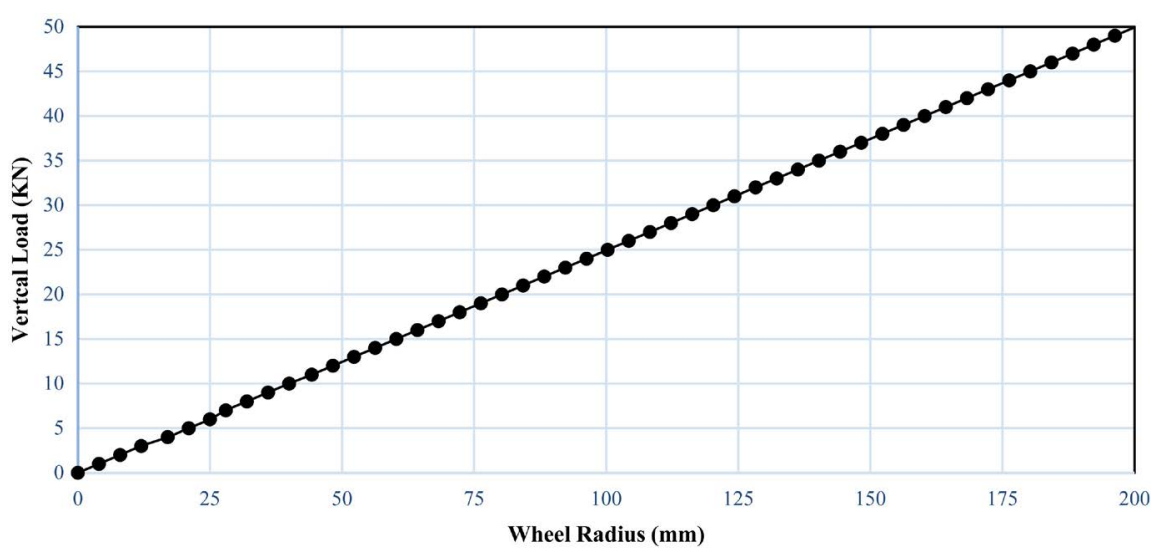

Figure 4. Vertical load vs. wheel radius curve.
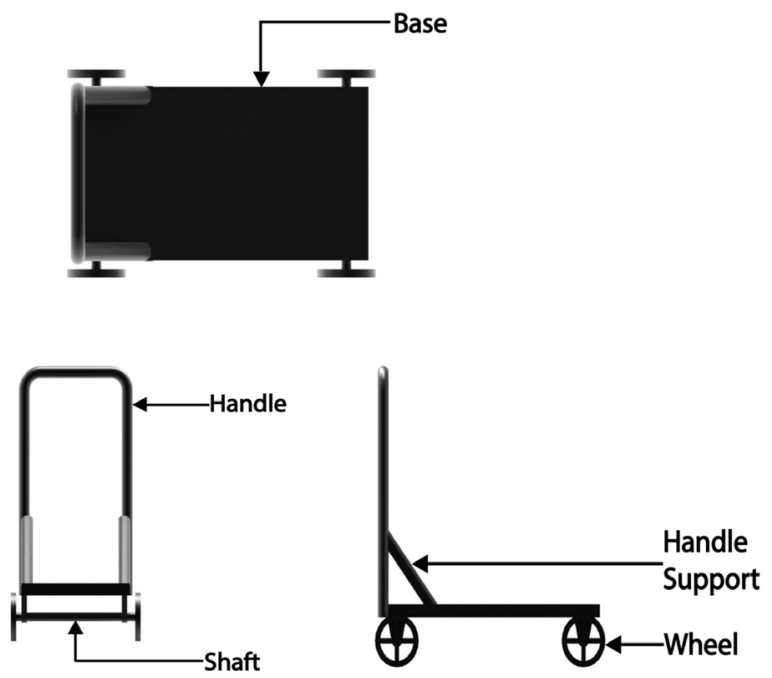

Figure 5. 2D view of an industrial trolley.

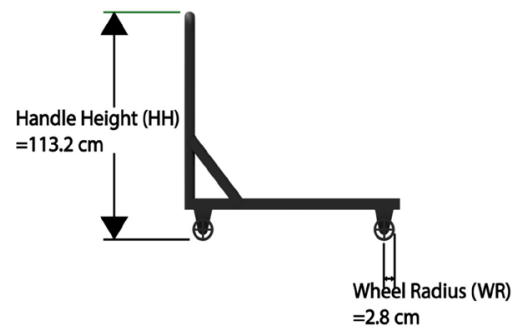

Existing Trolley Dimension

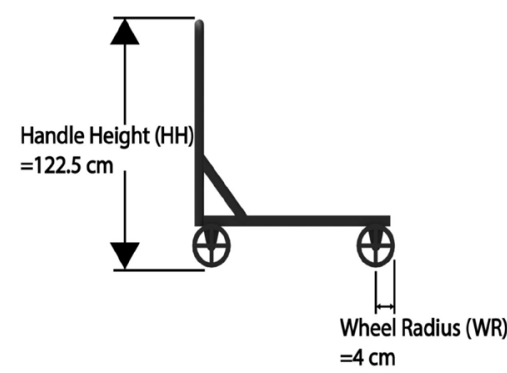

Proposed Trolley Dimension

Figure 6. Comparison of existing dimension and proposed dimension of an industrial trolley. 
So in this research, a new trolley was introduced based on workers' anthropometric measurements to increase their efficiency in workplace. For handle height mismatch percentage was lower than before, wheel radius was found out from the graph. So it can be said that proposed trolley is more acceptable than the previous one.

\section{Conflicts of Interest}

The authors declare no conflicts of interest regarding the publication of this paper.

\section{References}

[1] Zhang, Q., Song, M.M., Xiao, S.G. and Luo, Z. (2017) A Study on Design Method of Intelligent Platform Trolley. IOP Conference Series: Materials Science and Engineering, 274, Article ID: 012135. https://doi.org/10.1088/1757-899X/274/1/012135

[2] Joshi, S.N., Patki, V.K., Dixit, P.S. and Bhaldar, H. (2019) Design and Development of Human Following Trolley.

[3] Hutasuhut, F. and Erwin (2016) Development of Anthropometric Chair Based on Arm Span, Knee Height, and Sitting Height for Elderly. International Journal of GEOMATE, 11, 2844-2850.

[4] Shiwarkar, S.S., Pairag, S.D. and Zaveri, S.R. (2018) Design and Fabrication of Easy Handling Trolley. International Research Journal of Engineering and Technology, 5, 1690-1694.

[5] Talapatra, S. and Uddin, M. (2019) Prioritizing the Barriers of TQM Implementation from the Perspective of Garment Sector in Developing Countries. Benchmarking: An International Journal, 26, 2205-2224. https://doi.org/10.1108/BIJ-01-2019-0023

[6] Talapatra, S., Uddin, M. and Rahman, M. (2018) Development of an Implementation Framework for Integrated Management System Based on the Philosophy of Total Quality Management. American Journal of Industrial and Business Management, 8, 1507-1516. https://doi.org/10.4236/ajibm.2018.86101

[7] Biswas, B.B., Zahid, F.B., Ara, R., Parvez, M.S. and Hoque, A.S. (2014) Mismatch between Classroom Furniture and Anthropometric Measurements of Bangladeshi Primary School Students. 2014 International Conference on Mechanical, Industrial and Energy Engineering, Khulna, Bangladesh, 25-26 December 2014, 1-6.

[8] Castellucci, I., Arezes, P. and Viviani, C. (2010) Mismatch between Classroom Furniture and Anthropometric Measures in Chilean Schools. Applied Ergonomics, 41, 563-568. https://doi.org/10.1016/j.apergo.2009.12.001

[9] Parvez, M.S., Rahman, A. and Tasnim, N. (2019) Ergonomic Mismatch between Students Anthropometry and University Classroom Furniture. Theoretical Issues in Ergonomics Science, 20, 603-631. https://doi.org/10.1080/1463922X.2019.1617909

[10] Parvez, M.S., Parvin, F., Shahriar, M.M. and Kibria, G. (2018) Design of Ergonomically Fit Classroom Furniture for Primary Schools of Bangladesh. Journal of Engineering, 2018, Article ID: 3543610. https://doi.org/10.1155/2018/3543610

[11] Culvenor, J. (2005) Initial Force and Desirable Handle Height Range When Pushing a Trolley. Journal of Occupational Health and Safety-Australia and New Zealand, 21, 341-349.

[12] Kumar, W., Santhiyagu, V., Vasudev, K. and Solomon, D. (2017) Reduction of Dis- 
comfort in Pushing an Industrial Trolley Using Ergonomics. IOP Conference Series. Materials Science and Engineering, 263, Article ID: 062042. https://doi.org/10.1088/1757-899X/263/6/062042

[13] Wang, B., Wang, Y. and Lin, H.J. (2011) A New Type of Pig Handling Trolley, Applied Mechanics and Materials, 84-85, 347-351. https://doi.org/10.4028/www.scientific.net/AMM.84-85.347

[14] Thete, V., Patil, R., Sarange, R., Shinde, T. and Awate, S. (2018) Design and Development of a Material Handling Trolley Operated by Self-Weight of the Job. AIP Conference Proceedings, 2018, Article ID: 020001. https://doi.org/10.1063/1.5058238

[15] Talapatra, S. and Uddin, M.K. (2018) Some Obstacles that Affect the TQM Implementation in Bangladeshi RMG Sector: An Empirical Study. Proceedings of the 8 th International Conference on Industrial Engineering and Operations Management, Bandung, Indonesia, 6-8 March 2018.

[16] Talapatra, S. and Uddin, M.K. (2017) Understanding the Difficulties of Implementing TQM in Garments Sector: A Case Study of Some RMG Industries in Bangladesh. 2017 International Conference on Mechanical, Industrial and Materials Engineering, Rajshahi, 28-30December 2017.

[17] Resnick, M.L. and Chaffin, D.B. (1995) An Ergonomic Evaluation of Handle Height and Load in Maximal and Submaximal Cart Pushing. Applied Ergonomics, 26, 173-178. https://doi.org/10.1016/0003-6870(95)00014-4

[18] Parvez, M.S. and Shahriar, M. (2018) Agricultural Farm-Related Injuries in Bangladesh and Convenient Design of Working Hand Tools. Journal of Healthcare Engineering, 2018, Article ID: 4273616. https://doi.org/10.1155/2018/4273616

[19] Endo, Y. and Sakamoto, M. (2014) Correlation of Shoulder and Elbow Injuries with Muscle Tightness, Core Stability, and Balance by Longitudinal Measurements in Junior High School Baseball Players. Journal of Physical Therapy Science, 26, 689-693.

[20] Van Der Woude, L.H.V., Van Konlngsbruggen, C.M., Kroes, A.L. and Kingma, I. (1995) Effect of Push Handle Height on Net Moments and Forces on the Musculoskeletal System during Standardized Wheelchair Pushing Tasks. Prosthetics and Orthotics International, 19, 188-201.

[21] S. Wilkinson, W. (2000) Designing Trolleys for the New Millennia: An Engineering Analysis and Human Factors Concepts Approach. Proceedings of the Human Factors and Ergonomics Society Annual Meeting, 44, 405-405. https://doi.org/10.1177/1541931200044029131

[22] Okunribido, O.O. and Haslegrave, C.M. (1999) Effect of Handle Design for Cylinder Trolleys. Applied Ergonomic, 30, 407-419. https://doi.org/10.1016/S0003-6870(98)00053-2

[23] Aydin, A. and Kurtmen, E. (2018) The Design and Production of Transfer Trolleys Used In Marble Industry.

[24] Timbadia, V. and Bhat, R. (2018) Development of Multi-Purpose Trolley.

[25] Hussein, M. (2013) Design and Analysis of Office Trolley.

[26] Fothergill, D., Grieve, D.W. and Pheasant, S.T. (1992) The Influence of Some Handle Designs and Handle Height on the Strength of the Horizontal Pulling Action. Ergonomics, 35, 203-212. https://doi.org/10.1080/00140139208967807

[27] Adu, G. (2015) Mismatch between Office Furniture and Anthropometric Measures in Ghanaian Institutions. International Journal of Innovative Research in Science, Engineering and Technology, 4, 2687-2693. https://doi.org/10.15680/IJIRSET.2015.0402005 
[28] AL-Eisawi, K.W., Kerk, C., Jerome, C., Alfred, A.A., Omer, C.J. and Gaines, W.G. (1098) The Effect of Handle Height and Cart Load on the Initial Hand Forces in Cart Pushing and Pulling. Ergonomics, 42, 1099-1113. https://doi.org/10.1080/001401399185162

[29] Gite, L.P. and Yadav, B.G. (1990) Optimum Handle Height for a Push-Pull Type Manually-Operated Dryland Weeder. Ergonomics, 33, 1487-1494. https://doi.org/10.1080/00140139008925348

[30] Wollesen, B., Argubi-Wollesen, A., Leitner, M., Schulz, S., Keuchel, M., et al. (2017) Development and Development of an Ergonomic Handle and Wheel Design for Industrial Transport Carts. Global Environment, Health and Safety, 1, 9.

[31] Lin, J.-H., McGorry, R. and Chang, C.-C. (2011) Effects of Handle Orientation and between-Handle Distance on Bi-Manual Isometric Push Strength. Applied Ergonomics, 43, 664-670. https://doi.org/10.1016/j.apergo.2011.10.004

[32] Jung, M.-C., Haight, J. and Freivalds, A. (2005) Pushing and Pulling Carts and Two-Wheeled Hand Trucks. International Journal of Industrial Ergonomics, 35, 79-89. https://doi.org/10.1016/j.ergon.2004.08.006

[33] Biman, D., Julia, W. and Bijon, D. (2002) Ergonomics Evaluation and Redesign of a Hospital Meal Cart. Applied Ergonomics, 33, 309-318. https://doi.org/10.1016/S0003-6870(02)00018-2

[34] Seid, S. (2013) Ergonomics Assessment of Passenger Seats of Mini-Buses in Ethiopia. Global Journal of Researches in Engineering Industrial Engineering, 13, 112-118.

[35] Talapatra, S., Uddin, M., Antony, J., Shivam, G. and Elizabeth, C. (2019) An Empirical Study to Investigate the Effects of Critical Factors on TQM Implementation in the Garment Industry in Bangladesh. International Journal of Quality \& Reliability Management. (In Press) https://doi.org/10.1108/IJQRM-06-2018-0145

[36] Talapatra, S. and Rahman, M.H. (2016) Safety Awareness and Worker's Health Hazards in the Garments Sector of Bangladesh. European Journal of Advances in Engineering and Technology, 3, 44-49.

[37] Hayes, K., Walton, J.R., Szomor, Z. and Murrell, G. (2001) Reliability of Five Methods for Assessing Shoulder Range of Motion. The Australian Journal of Physiotherapy, 47, 289-294. https://doi.org/10.1016/S0004-9514(14)60274-9

[38] Wang, C.-Y. and Cai, D.-C. (2017) Hand Tool Handle Design Based on Hand Measurements. MATEC Web of Conferences, 119, Article ID: 01044. https://doi.org/10.1051/matecconf/201711901044

[39] Wu, S.-P. and Hsieh, C.-S. (2002) Ergonomics Study on the Handle Length and Lift Angle for the Culinary Spatula. Applied Ergonomics, 33, 493-501. https://doi.org/10.1016/S0003-6870(02)00024-8

[40] Sharma, G.N., Joshi, M., Kher, S. and Kothari, A. (1996) Mobile Trolley for Material Handling: Design Approach. Proceedings of the 35 th SICE Annual Conference. International Session Papers, Tottori, Japan, 24-26 July 1996, 1421-1424. 